\title{
Knowledge and Practice of Breast Self-Examination among Female Undergraduates in South-Eastern Nigeria
}

\author{
Ebirim Chikere Ifeanyi Casmir*, Nwoke Eunice Anyalewechi, Ibe Sally Nkechi Onyeka, \\ Amadi Chinasa Orie Agwu, Nwufo Chinyere Regina

\begin{abstract}
Department of Public Health, Federal University of Technology, Owerri, Nigeria
Email: *chayke2000@yahoo.com, eunnynwoks@yahoo.com, sallyibe@yahoo.com, nasaamadi93@yahoo.com, chinyerenwufo@yahoo.com
\end{abstract}

Received 25 May 2015; accepted 19 September 2015; published 22 September 2015

Copyright (C) 2015 by authors and Scientific Research Publishing Inc.

This work is licensed under the Creative Commons Attribution International License (CC BY). http://creativecommons.org/licenses/by/4.0/

(c) (i) Open Access

\section{Abstract}

Breast disease often presents as palpable masses (lumps), inflammatory lesions, nipple secretion, or mammography abnormalities; and this can be easily treated when discovered early. Breast Self-Examination (BSE) is the quickest and cheapest means of early breast cancer detection. The objective of this study was to determine the knowledge and practice of breast self-examination among female undergraduates in Owerri, south eastern Nigeria. A multi-stage sampling design was used to select participants. Interview using structured questionnaire was conducted on randomly selected respondents in six faculties from each tertiary institution. Questionnaire was prepared in English and was self-administered. Permission to conduct the survey was requested and obtained from the university ethical review board. Informed verbal and written consent was obtained from participants. Confidentiality of information was maintained throughout the study. Knowledge and practice of BSE was examined among 720 randomly selected female undergraduates aged 16 to 28 years. It was found that 98.9 percent have heard of BSE but only 32.5 percent of them performed this examination accurately and monthly as required. There is a statistically significant relationship between knowledge of risk factors for breast cancer and practice of BSE $\left(\chi^{2}=31.17, \mathrm{P}<0.001\right)$, source of information on BSE and practice of BSE $\left(\chi^{2}=86.75, \mathrm{P}<0.001\right)$ and the age of the respondents and practice of BSE $\left(\chi^{2}=75.94, \mathrm{P}<0.001\right)$. These female undergraduates had a poor knowledge of the right procedure and practice of BSE; therefore there is need for awareness creation on the risks of breast cancer and benefits of early detection among female undergraduates through breast self-examination.

\section{Keywords}

Breast Self-Examination, Undergraduate, Breast Cancer, Owerri, South-Eastern Nigeria

\footnotetext{
${ }^{*}$ Corresponding author.
}

How to cite this paper: Casmir, E.C.I., Anyalewechi, N.E., Onyeka, I.S.N., Agwu, A.C.O. and Regina, N.C. (2015) Knowledge and Practice of Breast Self-Examination among Female Undergraduates in South-Eastern Nigeria. Health, 7, $1134-1141$. 


\section{Introduction}

Breast Self-Examination (BSE) is a technique in which a woman examines her own breasts by seeing and feeling with fingers to detect breast lump. The purpose of breast self-examination is to increase familiarity with breast, to detect presence of lump in the breast at an early stage and to look for any abnormal changes in the breast [1]. Self examination of the breast each month between the $7^{\text {th }}$ and $10^{\text {th }}$ day of the menstrual cycle is the simplest yet extremely important way to detect breast cancer at the early stage of growth [2]. The BSE technique involves palpation of the breasts for lump with the tips of the fingers, rather than the flat of the hand. The woman would be in the erect position, either sitting or standing and while lying down. It has been observed that women can detect $95 \%$ of breast cancers and $65 \%$ of early minimal breast cancers through BSE [3].

Breast cancer is the most common cause of cancer death among women worldwide [4]. Globally, it has been reported that breast cancer ranks as the fifth cause of death from cancer overall, although still the leading cause of cancer mortality in women (the 411,000 annual deaths represent $14 \%$ of female cancer deaths) [5]. The WHO estimated that 1.2 million cases of breast cancer are diagnosed worldwide each year which represented $10 \%$ of all diagnosed cancers and constituted 22\% of all new cases in women in 2000 making it by far the most common cancer in women [6]. In Nigeria, breast cancer has been reported as the most common cancer in women and the second leading cause of death [7] [8]. Late presentation of patients at advanced stages of when little or no benefit can be derived from any form of therapy is the hallmark of breast cancer in Nigerian women [9]. The peak age incidence of breast cancer in Nigeria is reported to be between 45 - 50 years [2], In contrast to Europe and America where it was reported to be 65 - 75 years. Some cases have been reported below 30 years in Nigeria [10]. The three screening methods recommended for breast cancer include Breast Self-Examination (BSE), clinical breast examination (CBE) and mammography. Unlike CBE and mammography which require hospital visit and specialized equipment and expertise, BSE is inexpensive and carried out by women themselves. Although mammography remains the best diagnostic tool in the detection of breast cancer, it is not routinely performed in Nigeria because of cost, high technology equipment and expertise required. Mammograms miss most breast lump in the younger age groups; this is likely to happen in Nigeria where cases below 30 have been reported [11].

To reduce the burden of breast cancer in Nigeria, it is necessary to first determine the level of knowledge and practice (skill) relating to breast self-examination as a breast cancer prevention strategy especially among our teaming youths who at this stage of life can continue this practice to adulthood. Therefore this study was aimed to identify the level of knowledge and practice of breast self-examination among female undergraduates in Owerri, south eastern Nigeria.

\section{Methodology}

\subsection{Design, Setting and Sample}

A descriptive-cross sectional survey was used to gather data relevant for this study. Data was collected from $20^{\text {th }}$ February to $16^{\text {th }}$ April 2015. The study sample consisted of systematic randomly selected female undergraduates from four tertiary institutions in Owerri. These institutions include Federal University of Technology (FUTO), Imo State University (IMSU), Alvan Ikoku Federal College of Education (AIFCE) and Federal Polytechnic Nekede (FPN), all in Owerri South-east, Nigeria. A multi-stage sampling design was used to select 720 undergraduates who participated in the study. The students were first stratified by their institution of higher learning. Second stage was the selection of six faculties from each of the institutions and lastly these undergraduates were randomly selected to participate in the study after proportionate allocation of required sample from each institution.

\subsection{Instrument}

Interview using structured questionnaire was conducted on the randomly selected respondents in six faculties from each tertiary institution. Questionnaire was prepared in English and was self-administered. It was administered after explaining the purpose of the study and criteria used in selecting each respondent. Students who gave their consent to participate were given a structured and pretested self administered questionnaire. Information was collected on demographic characteristics, knowledge and practice of breast self-examination, family history of breast cancer, knowledge of the risk factors of breast cancer, perception breast self-examination and Barriers 
to the practice of breast self-examination.

\subsection{Data Collection}

Permission to conduct the survey was requested and obtained from the university ethical review board. Informed verbal and written consent was obtained from participants. Confidentiality of information was maintained throughout the study. Students who gave their consent to participate were given a structured and pretested self administered questionnaire

\subsection{Statistical Analysis}

The data collected were analyzed using Statistical Package for Social Sciences (SPSS version 21.0) for windows. Proportions were used to summarize responses for all demographic, knowledge and practice items. Knowledge of risk factor for breast cancer was evaluated and scores classified under good or poor knowledge. Also knowledge of breast self-examination was assessed, chi-square analysis was used to investigate significant relationship between two categorical variables, and all analysis was considered statistically significant at $\mathrm{P}<0.05$ significant level (2-tailed).

\section{Results}

\subsection{Characteristics of the Study Participants}

The sample studied includes 186 (25.8\%) of IMSU students, 172 (23.9\%) of FUTO students, 196 (27.2\%) of FPN students and 166 (23.1\%) of AIFCE students. The age of the respondents ranged from 16 to 28 years. Majority were in the age group of $20-24$ years $(n=294,40.8 \%)$, while only $168(23.3 \%)$ were aged above 24 years. The mean age was $21.9 \pm 2.7$ years.

\subsection{Knowledge and Practice of Breast Self-Examination among Female Undergraduates}

Seven hundred and twelve (98.9\%) respondents reported they have heard of breast self-examination. Five hundred and fifty-two (76.7\%) reported they practiced BSE, Furthermore, 42 (5.8\%) respondents reported they had siblings or mother that has breast cancer, 30 (4.2\%) had a relative with ovarian and cervical cancer. Sixty (8.3\%) revealed they had observed lump in their breast during self examination, but only 24 (3.3\%) had been diagnosed of breast cancer by a medical practitioner as documented in Table 1 . But further investigation revealed that only 234 (32.5\%) of the respondents performed breast Self-Examination accurately and monthly as required (Figure 1).

There was a statistically significant relationship $\left(\chi^{2}=11.53\right.$, P-value $\left.=0.001\right)$ between knowledge of risk factor for breast cancer and practice of breast self-examination, which showed that 80.1 percent of respondents with good knowledge of breast cancer risk factors practiced breast self-examination. With regards to source of knowledge, there was a statistically significant relationship $\left(\chi^{2}=86.75\right.$, P-value $\left.<0.001\right)$ between the source of information on breast self-examination and the practice of breast self-examination, which show that the most effective source of information was from health professionals (88.1\%) followed by television and radio programmes $(78.6 \%)$ on breast cancer prevention. Furthermore, there was statistically significant relationship $\chi^{2}=$ 75.94, P-value $<0.001$ ) between the age of the respondents and the practice of breast self-examination, which also indicated that as the age increases there was an increase in proportion of undergraduate who practiced breast self-examination, as shown in Table 2 .

\subsection{Knowledge of Risk Factors for Breast Cancer among Female Undergraduates}

Out of 720 respondents, 438 (60.8\%) indicated that age is a risk factor for cancer, 426 (59.2\%) stated that a woman who has never given birth to an infant capable of survival is at risk. 312 (43.3\%) knew that a girl that started her menstruation before the age of 12 years (early onset of menarche) is at risk, 606 (84.2\%) stated that those with family history of breast cancer are at risk, 402 (55.8\%) reported that obesity after menopause is a risk, $558(75.5 \%)$ indicated that recent or long term use of oral contraceptive and hormone replacement therapy is a risk factor for breast cancer. Only 216 (30\%) indicated that breast feeding a child is a risk factor for breast cancer. Also 540 (75.0\%) indicated that alcohol consumption and tobacco smoking were also risk factors of breast cancer. As shown in Table 3. 
Table 1. Knowledge and practice of BSE among female undergraduates.

\begin{tabular}{|c|c|c|}
\hline Breast self-examination variables & Frequency $(N=720)$ & Percentage (\%) \\
\hline \multicolumn{3}{|l|}{ Have an Idea of breast self-examination } \\
\hline Yes & 712 & 98.9 \\
\hline No & 8 & 1.1 \\
\hline \multicolumn{3}{|l|}{ Practice breast self-examination } \\
\hline Yes & 552 & 76.7 \\
\hline No & 168 & 23.3 \\
\hline \multicolumn{3}{|l|}{ Frequency of breast self-examination Performance } \\
\hline Monthly & 312 & 43.3 \\
\hline Once in two months & 66 & 9.2 \\
\hline Once in six months & 108 & 15.0 \\
\hline Yearly & 66 & 9.2 \\
\hline None & 168 & 23.3 \\
\hline \multicolumn{3}{|l|}{ Have Siblings or Mother with Breast Cancer } \\
\hline Yes & 42 & 5.8 \\
\hline No & 678 & 94.2 \\
\hline \multicolumn{3}{|c|}{ Have a Relative with Ovarian, Cervical or Prostate Cancer } \\
\hline Yes & 30 & 4.2 \\
\hline No & 690 & 95.8 \\
\hline \multicolumn{3}{|l|}{ Have Observed Lump in my Breast } \\
\hline Yes & 60 & 8.3 \\
\hline No & 660 & 91.7 \\
\hline \multicolumn{3}{|l|}{ Diagnosed of Breast Cancer } \\
\hline Yes & 24 & 3.3 \\
\hline No & 696 & 96.7 \\
\hline
\end{tabular}

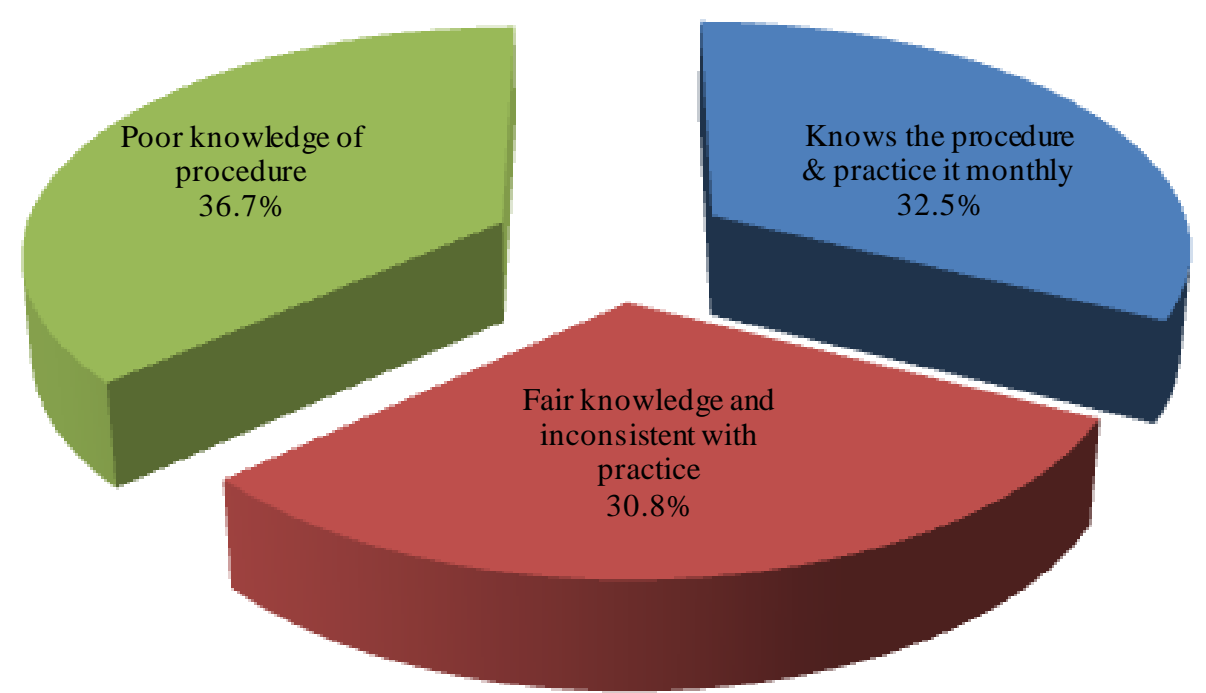

Figure 1. Distribution of undergraduates with accurate knowledge and consistent in the practice of BSE. 
Table 2. Relationship between knowledge of risk factors for breast cancer, source of knowledge, age of respondent and practice of breast self examination.

\begin{tabular}{|c|c|c|c|}
\hline Knowledge of risk factors of breast cancer & \multicolumn{3}{|c|}{ PRACTICE BREAST SELF-EXAMINATION } \\
\hline & Yes (\%) & No (\%) & Total \\
\hline Good knowledge & $410(80.1)$ & 102 (19.9) & 512 \\
\hline Poor knowledge & $142(68.3)$ & $66(31.7)$ & 208 \\
\hline \multirow[t]{2}{*}{ Total } & $552(76.7)$ & $168(23.3)$ & 720 \\
\hline & value $=0.00$ & & \\
\hline \multicolumn{4}{|l|}{ Source } \\
\hline From health professional & $312(88.1)$ & $42(11.9)$ & 354 \\
\hline From books/magazine & $114(73.1)$ & $42(26.9)$ & 156 \\
\hline From friends & $60(47.6)$ & $66(52.4)$ & 126 \\
\hline From Tv/radio/internet & $66(78.6)$ & $18(21.4)$ & 84 \\
\hline \multirow[t]{2}{*}{ Total } & $552(76.7)$ & $168(23.3)$ & 720 \\
\hline & value $<0.00$ & & \\
\hline \multicolumn{4}{|l|}{ Age (years) } \\
\hline$<20$ & $156(60.5)$ & $102(39.5)$ & 258 \\
\hline $20-24$ & $234(79.6)$ & $60(20.4)$ & 294 \\
\hline$>24$ & $162(96.4)$ & $6(3.6)$ & 168 \\
\hline Total & $552(76.7)$ & $168(23.3)$ & 720 \\
\hline \multicolumn{4}{|c|}{$\chi^{2}=75.939, d f=2, p$-value $<0.001$} \\
\hline
\end{tabular}

Table 3. Knowledge level of risk factors for breast cancer among female undergraduates.

\begin{tabular}{lcc}
\hline \multicolumn{1}{c}{ Knowledge of risk factors for breast cancer } & Frequency (N = 720) & Percentage (\%) \\
\hline Aging & 438 & 60.8 \\
A woman who has never given birth to an infant capable of survival & 426 & 59.2 \\
Late age at first full-term pregnancy (>30 years) & 414 & 57.5 \\
End menstruation $>55$ years & 282 & 39.2 \\
Start menstruation $<12$ years & 312 & 43.3 \\
Family history of breast cancer & 606 & 84.2 \\
Obesity after menopause & 402 & 55.8 \\
Recent or long term use of oral contraceptive and hormone replacement therapy & 558 & 77.5 \\
Breast feeding a child & 216 & 30.0 \\
Alcohol consumption and smoking & 540 & 75.0 \\
High dose radiation to chest & 612 & 85.0 \\
\hline
\end{tabular}

Final the overall knowledge of the respondents on the risk factors for breast cancer was assessed and scored, 512 (71.1\%) had good knowledge while 208 (28.9\%) had poor knowledge of the risk factors for breast cancer, as shown in Figure 2. 


\subsection{Perception of Undergraduate on Breast Self-Examination}

One hundred and thirty-eight (20.5\%) believed that the appropriate age to start breast self-examination is 18 years. Six hundred and ninety-six (96.7\%) admitted that breast self-examination is beneficial to them and 96 (13.3\%) believed they were susceptible to breast cancer.

\subsection{Barriers to Breast Self-Examination}

Two hundred and twenty-two (30.8\%) feel tickled performing breast self-examination, 198 (27.5\%) feel shy performing breast self-examination, 84 (11.7\%) believed breast self-examination take too much of their time, 18 (2.5\%) feel breast self-examination is unnecessary, 37 (5.1\%) indicated that they don't have enough privacy to perform BSE, $6(0.8 \%)$ felt that breast self-examination is expensive while 155 (21.5\%) preferred going to the hospital for breast examination (Figure 3).

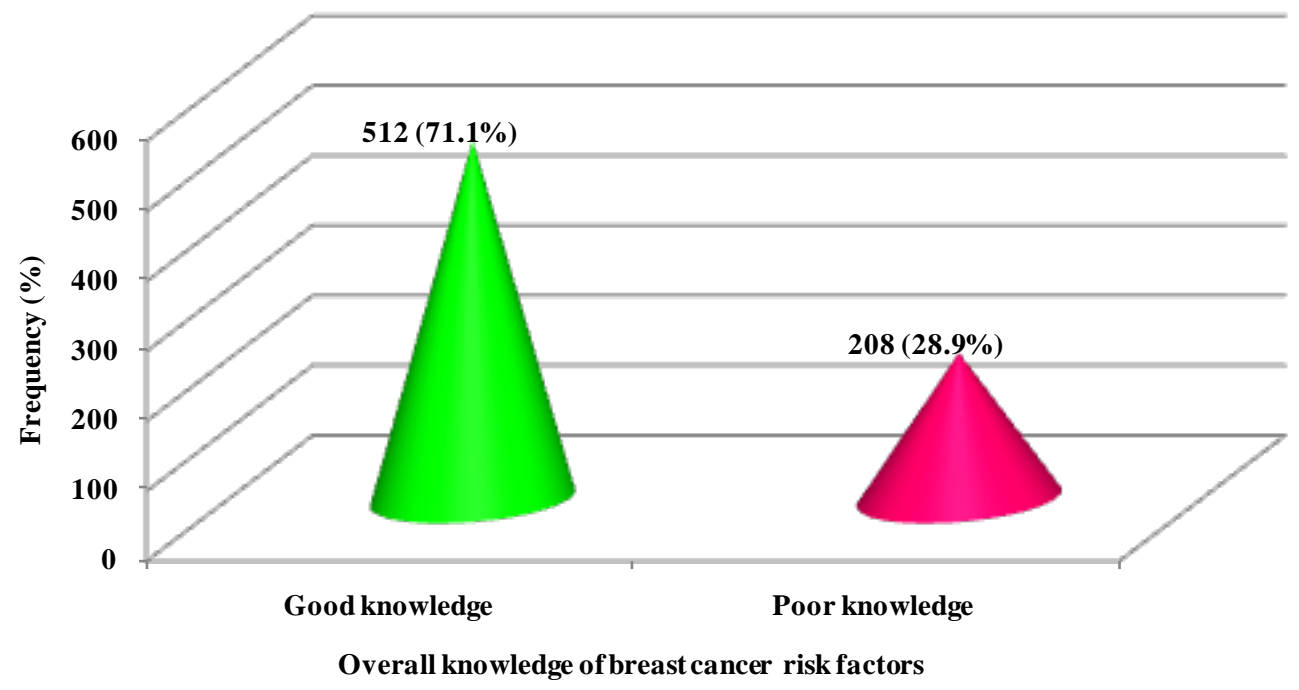

Figure 2. Overall knowledge of breast cancer risk factors among undergraduates.

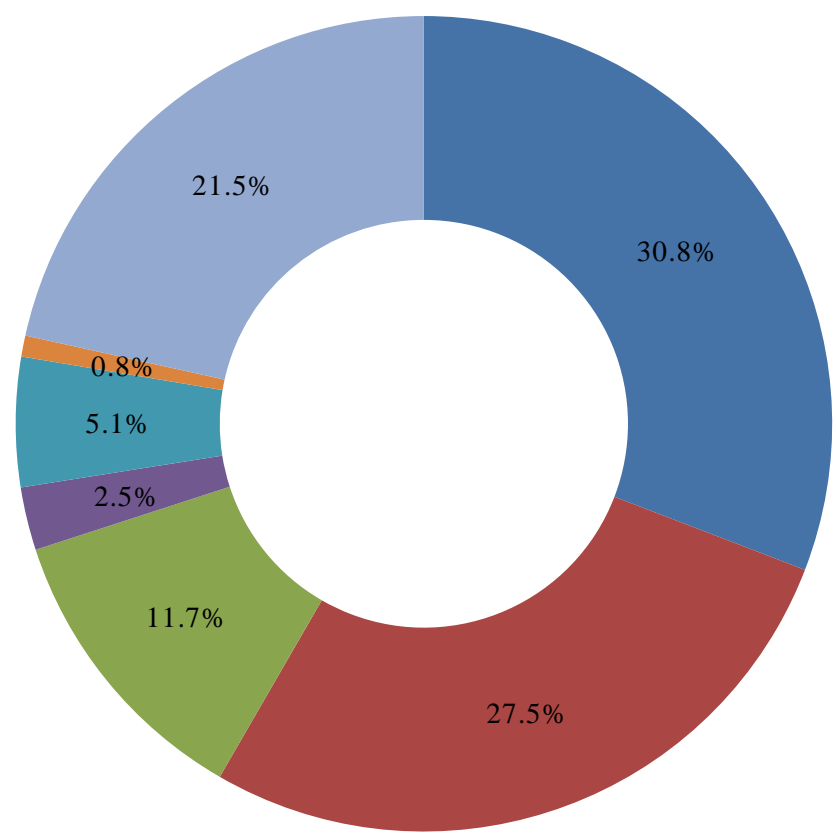

- Feel tickled perfoming BSE

- Feel shy perfoming BSE

- Believed BSE takes too much time

- Feel BSE is unnecessary

Don't have enough privacy to perform BSE

- Feel that BSE is expensive

- Preferred going to the hospital for breast examination

Figure 3. Barriers to the practice of breast self-examination. 


\section{Discussion}

The age of the respondents ranged from 16 years to 28 years and the mean age was $21.9 \pm 2.7$ years. The study was appropriate in this age group as most of them were young adults who should be more enlightened on breast cancer and breast self-examination before they reach the age of common occurrence of the disease. This is in line with advice from health experts who indicated that women should begin breast examination as early as age twenty [12].

In this study most of the respondents have heard of BSE (98.9\%), but only 76.7 percent of such respondents reported they practice breast self-examination. Further investigation indicated that only 32.5 percent could correctly described the procedure. Several studies on BSE such as have reported similar findings [13]. This may be as a result of poor health education in our society and also the perception that they cannot develop breast cancer. The health belief model (HBM) suggests that when a woman perceives herself at risk then she is more likely to practice BSE [14]. Since only 32.5 percent had adequate knowledge of BSE, the implication therefore is that 67.5 percent of such undergraduates cannot impact positively on their fellow students and general populace on the importance of BSE.

All the respondents (100\%) in this research have heard of breast cancer. Similar findings were reported in studies conducted in other regions of Nigeria where $97 \%$ and $92 \%$ of the respondents were aware of breast cancer, as a disease entity [15] [16]. The awareness of breast cancer among the respondents could be attributed to the level of education of the respondents, who are in tertiary institutions and are opportune to obtain information from various sources. The major source of information about breast cancer was from health professionals this is maybe due to the fact that the respondents had opportunity and access to health professionals while in school, at home and in the hospital. The least reported source information on breast cancer in the study was from television/radio/internet, this could be as a result of poor awareness creation by appropriate authorities through this media. Very low knowledge about symptoms of breast cancer and screening methods has also been reported in other studies in Nigeria [9] [13] [17]. I emphasized the need for female youths to be properly taught the routine of BSE, as this will greatly influence their practice as they grow older.

\section{Conclusions}

The observed wide gap between knowledge and practice could be reduced in our populace through articulated approach focusing on health education with well defined strategies. In addition, further studies are required to explore the reasons in the difference between knowledge and practice of breast self-examination. In the general population, especially those who live in the rural areas where the bulk of the disease is, access to information may still be a challenge.

It is therefore of utmost importance to launch educational programs to increase public awareness of the prevalence of breast cancer, its risk factors and the importance of BSE. Awareness should be enhanced by using all available means which include news media, schools, social networks, hospital waiting areas and distribution of health pamphlets.

\section{Acknowledgements}

The authors are grateful to the contribution of the undergraduates who participated in the study.

\section{Conflicts of Interest}

Authors have declared that no conflicts of interest exist.

\section{Authors' Contribution}

This work was carried out in collaboration between all authors. Author CICE wrote the protocol and did the statistical analysis. Authors EAN and SNOI did the study design and literature searches while authors COAA and CRN developed the questionnaire and proofread the manuscript. All authors read and approved the final manuscript.

\section{References}

[1] Deaton, J.G. (1988) How to Recognize Cancer before It’s Too Late. Herald of Health, June, 9-11. 
[2] Abudu, E.K., Banjo, A.A.F., Izegbu, M.C., Agboola, A.O.J., Anunobl, C.C. and Musa, A. (2007) Malignant Breast Lesions at Olabisi Onabanjo University Teaching Hospital (OOUTH) Saganu: A Histopathological Review. Nigeria Postgraduate Medical Journal, 14, 57-59.

[3] Brunar, L.S. and Suddarth, D.S. (1988) Textbook of Medical Surgical Nursing. J. B. Lippincott Company, Philadelphia, 890-895.

[4] Bray, F., MacCarron, P. and Parkin, M. (2004) The Changing Global Pattern of Female Breast Cancer Incidence and Mortality. Breast Cancer Review, 6, 229-239.

[5] Parkin, D.M., Bray, F., Ferlay, J. and Pisani, P. (2005) Global Cancer Statistics, 2002. CA: A Cancer Journal for Clinicians, 55, 74-108. http://dx.doi.org/10.3322/canjclin.55.2.74

[6] Anderson, B.O., Braun, S., Lim, S., Robert, A., Taplin, S.S., et al. (2003) Early Detection of Breast Cancer in Countries with Limited Resources. The Breast Journal, 9, S51-S59. http://dx.doi.org/10.1046/j.1524-4741.9.s2.4.X

[7] American Cancer Society (2002) Cancer Statistics. CA: Am cancer l clin, 52, 10-11.

[8] Adebamowo, C.A. and Ajayi, O.O. (2000) Breast Cancer in Nigeria. West African Journal of Medicine, 19, $179-191$.

[9] Okobia, M.N., Bunker, C.H., Okonofua, F. and Osime, U. (2006) Knowledge, Attitude and Practices of Nigeria Women towards Breast Cancer: A Cross-Sectional Study. World Journal of Surgical Oncology, 4, 11-16. http://dx.doi.org/10.1186/1477-7819-4-11

[10] Okobia, M.N. and Osime, U. (2001) Clinicopathological Study of Carcinoma of the Breast in Benin City. African Journal of Reproductive Health, 5, 56-62. http://dx.doi.org/10.2307/3583430

[11] Anyanwu, S.N. (2007) Breast Cancer in Eastern Nigerian: A Ten-Year Review. West African Journal of Medicine, 19, 120-125.

[12] Smith, R.A., Cokkinides, V. and Brawleg, O.W. (2008) Cancer Screening in the United States, 2008: A Review of Current American Cancer Society Guidelines and Cancer Screening Issues. CA: A Cancer Journal for Clinicians, 58, 161-179.

[13] Odusanya, O.O. and Tayo, O.O. (2001) Breast Cancer Knowledge, Attitude and Practices among Nurses in Lagos, Nigeria. Acta Oncologica, 40, 844-848. http://dx.doi.org/10.1080/02841860152703472

[14] Bhakata, P. (1995) Asian Women’s Attitudes to Breast Self Examination. Nursing Times, 91, 44-47.

[15] Ekanem, I.A. and Etukudo, M.H. (1990) Cancer Information Survey among Students in Calabar University and School of Nursing, UCTH, Calabar, Nigeria. Nigerian Medical Journal, 20, 32-34.

[16] Oyeka, I.C.A. and Ezeama, M.M. (1997) Breast Cancer; Information Gap among Female School Teachers in Nigeria. Orient Journal of Medicine, 9, 18-20.

[17] Uche, E.E. (1999) Cancer Awareness among a Nigeria Population. Tropical Doctor, 29, 39-40. 